\title{
Portomesenteric vein thrombosis following laparoscopic sleeve gastrectomy: are underlying haematological disorders the culprit?
}

\author{
Kevin Bain, Vickie Kassapidis, Vadim Meytes, George Ferzli
}

NYU Langone Hospital Brooklyn, Brooklyn, New York, USA

\section{Correspondence to Dr Kevin Bain kevin.bain@nyumc.org}

Accepted 6 February 2018

\section{DESCRIPTION}

A 51-year-old woman with a medical history of hypothyroidism and deep vein thrombosis (DVT) during pregnancy presented to the emergency department 5 days after laparoscopic sleeve gastrectomy (LSG) complaining of worsening abdominal pain and low-grade fevers. A CT scan and upper gastrointestional series were performed with no evidence of leak or abscess, and the patient was admitted for observation.

On hospital day 2, the patient had worsening abdominal pain and an episode of emesis. An ultrasound revealed a new moderate amount of intraperitoneal-free fluid. A CT scan was repeated which revealed a segmental non-occlusive thrombus in the splenic vein (figure 1) as well as an occlusive thrombus in the superior mesenteric vein near the portosplenic confluence (figure 2).

On further discussion, the patient admitted to a previous diagnosis of antithrombin III deficiency and non-compliance with anticoagulation. The patient was subsequently started on therapeutic anticoagulation with resolution of her abdominal pain. The remainder of the hospitalisation was uncomplicated, and she was discharged home on oral anticoagulation, with recommendations to continue as lifelong therapy.

Portomesenteric vein thrombosis (PMVT) is a rare but serious postoperative complication following laparoscopic bariatric procedures, with an incidence rate ranging from $0.3 \%$ to $1 \%{ }^{1}$ Due to the non-specific presenting symptoms of PMVT, a high index of suspicion is needed in order to make the diagnosis. ${ }^{1-3}$ Abdominal CT scan is the imaging modality of choice and carries a diagnostic sensitivity of $90 \% .^{2}$ If left untreated, PMVT can progress to significant portal hypertension, intestinal ischaemia, intestinal perforation and peritonitis. ${ }^{2}$

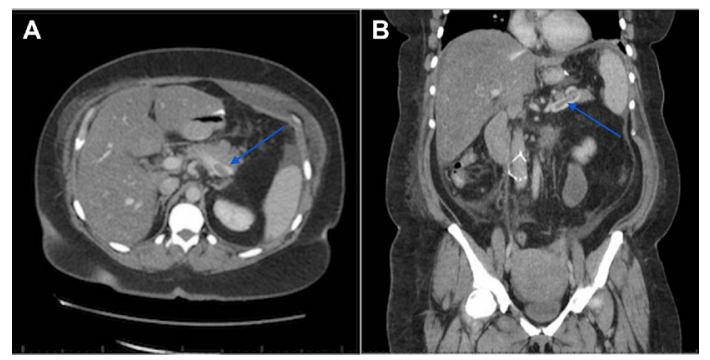

Figure 1 (A, B) Segmental non-occlusive thrombus (blue arrow) in the splenic vein.

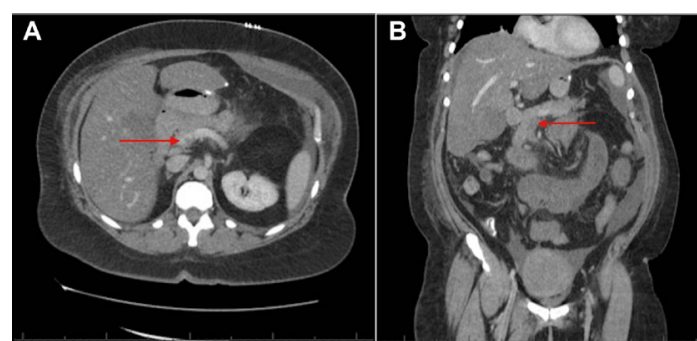

Figure 2 ( $A, B)$ Occlusive thrombus (red arrow) in the superior mesenteric vein near the portosplenic confluence.

It has been well established that morbid obesity is a significant prothrombotic factor for patients undergoing bariatric procedures. ${ }^{1-3}$ There has been increasing interest in identifying other factors which may contribute to hypercoagulability during these procedures. Possible aetiologies for PMVT following LSG include thrombophilia, venous stasis from increased intra-abdominal pressure or patient positioning, and intraoperative manipulation of splanchnic and portal vasculature. $^{13}$

Increasing interest has turned towards identifying patients who may be predisposed to PMVT following LSG. In a recent multicentre review

\section{Learning points}

Patients undergoing laparoscopic sleeve gastrectomy (LSG) have an increased risk of developing portomesenteric vein thrombosis (PMVT), which is a rare but serious complication.

- The most common presenting symptom is abdominal pain; however, due to its non-specific presentation, a high index of clinical suspicion is important. With prompt diagnosis, $90 \%$ of PMVT after LSG can be successfully treated with therapeutic anticoagulation alone. Continued therapy commonly lasts between 3 and 6 months.

- Haematological abnormalities have been documented in up to $92 \%$ of PMVT following LSG, with the most common abnormality being Factor VIII elevation. Patients who may be at risk for thromboembolic events (eg, history/ family history) should be considered for preoperative thrombophilia workup. 
of 40 patients who developed PMVT after LSG, 92\% had a haematological abnormality. The most common abnormality identified was elevation of Factor VIII (76\%). ${ }^{1}$ Other significant abnormalities included deficiencies in antithrombin III, factor V Leiden and protein $\mathrm{C} / \mathrm{S}$.

Failure to diagnose PMVT after LSG predisposes patients to emergent surgical intervention. However, with prompt diagnosis and expeditious treatment, up to $90 \%$ can be successfully treated with therapeutic anticoagulation alone. ${ }^{1}$ For these patients, the duration of anticoagulation remains somewhat ambiguous. Oral anticoagulation therapy is usually continued for at least 3-6 months. It is recommended to obtain formal haematological consultation, with individualised circumstantial consideration for indefinite anticoagulation. ${ }^{13}$

Contributors $\mathrm{KB}, \mathrm{VK}$ and VM: writing and editing. All authors: final editing and submission.
Competing interests None declared.

\section{Patient consent Obtained.}

Provenance and peer review Not commissioned; externally peer reviewed.

(C) BMJ Publishing Group Ltd (unless otherwise stated in the text of the article) 2018. All rights reserved. No commercial use is permitted unless otherwise expressly granted.

\section{REFERENCES}

1 Parikh M, Adelsheimer A, Somoza E, et al. "Factor VIII elevation may contribute to portomesenteric vein thrombosis after laparoscopic sleeve gastrectomy: a multicenter review of 40 patients". Surgery for obesity \& related diseases 1835;2017:13.

2 Salinas J, Barros D, Salgado N, et al. Portomesenteric vein thrombosis after laparoscopic sleeve gastrectomy. Surg Endosc 2014;28:1083-9.

3 Goitein D, Matter I, Raziel A, et al. Portomesenteric thrombosis following laparoscopic bariatric surgery: incidence, patterns of clinical presentation, and etiology in a bariatric patient population. JAMA Surg 2013;148:340-6.

Copyright 2018 BMJ Publishing Group. All rights reserved. For permission to reuse any of this content visit http://group.bmj.com/group/rights-licensing/permissions.

BMJ Case Report Fellows may re-use this article for personal use and teaching without any further permission.

Become a Fellow of BMJ Case Reports today and you can:

- Submit as many cases as you like

- Enjoy fast sympathetic peer review and rapid publication of accepted articles

- Access all the published articles

- Re-use any of the published material for personal use and teaching without further permission

For information on Institutional Fellowships contact consortiasales@bmjgroup.com

Visit casereports.bmj.com for more articles like this and to become a Fellow 